\title{
COMUNIDADES DE APRENDIZAGEM: \\ EXPERIÊNCIA ACADÊMICA NO PROJETO \\ INTEGRADO EM GESTÃO DA INFORMAÇÃO
}

\author{
Maria do Carmo Duarte Freitas \\ Helena de Fátima Nunes Silva \\ Patrícia Zeni Marchiori \\ Sônia Maria Breda
}

\begin{abstract}
Resumo
Reflexão sobre o ensino superior baseada no relato da experiência do Projeto Integrado em Gestão da Informação (PIGI), do Curso de Gestão da Informação da Universidade Federal do Paraná. Discorre sobre os traços distintivos do atual mundo do trabalho e sua relação com a formação universitária. Expõe os fundamentos das comunidades de aprendizagem. Descreve a proposta e a metodologia do PIGI. Apresenta dados de avaliação do Projeto, ressaltando os ganhos para docentes e discentes envolvidos e elencando sugestões para aprimoramento do processo formativo do gestor da informação. Destaca os elementos "prática" e "compartilhamento" como pontos altos dessa experiência, que se pode constituir em ensaio para efetivação de uma comunidade de aprendizagem.
\end{abstract}

\section{Palavras-Chave}

Educação Superior - metodologias de ensino; Ensino Superior; Comunidades de Aprendizagem - Experiências; Gestão da Informação formação profissional

\section{INTRODUÇÃO}

$\mathrm{O}$ advento das novas tecnologias de comunicação e informação modificou, de maneira significativa, as formas e papéis da educação. Há que se repensar as teorias e práticas de ensino e pautar-se na compreensão dessa nova realidade social. A organização do cotidiano nas organizações educativas, especialmente naquelas voltadas ao ensino superior, carece de concepções didáticas e metodológicas que contemplem a construção do conhecimento a partir de experiências dos alunos perme- 
adas pela compreensão do contexto histórico, social, político, econômico no qual o estudante está inserido.

É necessário, também, observar as profundas transformações que ocorreram nas condições de mercado, nas tecnologias e nos valores relativos ao mundo do trabalho, adequando-se a formação acadêmica. No que se refere às condições de mercado, as características mais acentuadas foram a instabilidade e a diversificação da concorrência ligada à abertura dos mercados, que exigem das organizações a capacidade de adaptação rápida às mudanças.

As novas tecnologias, por sua vez, ao mesmo tempo em que criam oportunidades, requerem uma lógica organizacional que permita o desenvolvimento de competências e comportamentos para capacitar indivíduos a utilizá-las. Por outro lado, valores referentes ao mundo do trabalho, em que os futuros profissionais devem ser inseridos, exigem cada vez mais posturas flexíveis e participativas, estimuladoras da criatividade e iniciativa.

Portanto, além do esforço de compreensão do ser humano no cotidiano escolar, compete à universidade preparar seus educandos para a ação no complexo do mundo do trabalho, pleno de desafios próprios.
Muitas instituições de ensino continuam com a noção de que o aprendizado acontece individualmente, que existe um começo e um fim (currículo), que esse aprender deve preferencialmente ocorrer "em separado" de outras atividades e que o resultado principal deriva deste tipo de ensinamento. Sob outra ótica educativa, a da pedagogia histórico-crítica, evidencia-se a preocupação com diferentes espaços, metodologias e formas de educar, em que o ser humano constrói e vivencia seu próprio aprendizado, encontrando-se aí uma relação estreita com o conceito de comunidades de aprendizagem.

Nessa perspectiva, o aprendizado se dá por meio de experiências vividas de participação do homem no mundo. É um fenômeno que reflete fundamentalmente a natureza social dos seres humanos capazes de construir o saber negociado nas suas ações e relações com os outros.

A ação das pessoas, independente do ambiente (escolar ou trabalho), está associada à visão de mundo, a crenças e valores que envolvem a cognição. A cognição, objeto a ser considerado em todos os momentos da construção do saber, engloba aspectos emocionais, corporais e sociais que geram conhecimento tácito e estão amplamente presentes no cotidiano escolar e do trabalho. Bergman e Luckmann (1985), na perspectiva da sociologia do 
conhecimento, salientam que qualquer conhecimento resulta de uma gama de circunstâncias e que, na dialética da produção do conhecimento, está presente um universo de significados compartilhados.

As práticas pedagógicas na universidade necessitam buscar alternativas de efetivar um processo ativo de produção de significados para aquilo que ensinam. Um significado que seja dinâmico e histórico ao mesmo tempo, que busque a resolução de problemas e também a compreensão de que cada resolução não é nada mais do que uma tentativa incompleta, parcial, específica ou efêmera na busca de uma solução maior.

A experiência aqui apresentada teve como fio condutor a metodologia das comunidades de prática. Nesse sentido além de outros fatores, são necessários o domínio do conhecimento; a comunidade e a prática.

O domínio é o que dá aos membros um senso de empreendimento comum e os mantêm juntos. A comunidade busca os interesses no seu domínio, os membros participam de atividades conjuntas e discussões, ajudam uns aos outros e compartilham informações. A prática estabelece as ligações entre o domínio e as pessoas (comunidade) na resolução de problemas, ou seja, uma prática compartilhada.
As questões explicitadas impõem-se como objeto de reflexão da prática escolar e sua relação com o mundo do trabalho $\mathrm{e}$ constituem o ponto de partida deste artigo. Nesse sentido, o texto tece uma reflexão sobre a educação superior e os esforços voltados para o incremento do processo ensino-aprendizagem do Curso de Gestão da Informação da Universidade Federal do Paraná. Toma-se por base o relato de uma experiência acadêmica e suas possibilidades: o Projeto Integrado de Gestão da Informação (PIGI).

\section{ALTERNATIVAS DO ENSINO SUPERIOR}

A Sociedade da Informação tem como uma de suas características fundamentais a incorporação da velocidade, em todas as dimensões das relações e processos sociais. Neste contexto, a formação profissional em nível de graduação deve lançar mão de métodos e procedimentos que eduquem para a tolerância, criatividade, flexibilidade, capacidade de investigação, ética, entre outros, atrelando educadores e educandos na observância da ética e da cidadania. Nesse sentido, o Relatório Delors sobre a Educação enfatiza como condição necessária para as próximas gerações, quatro saberes fundamentais: aprender a aprender, aprender a fazer, aprender a ser e aprender a conviver (DELORS, 1999). 
Com esse olhar é possível demarcar a função educativa centrada na formação de sujeitos cognitivos com competências e habilidades para enfrentar situações inesperadas, solucionar problemas, acompanhar o desenvolvimento do conhecimento em suas áreas de interesse e respeitar a pluralidade cultural que permeia a sociedade.

A percepção de que o conhecimento e a aprendizagem são fatores propulsores dessa nova sociedade faz da universidade um espaço de construção e reflexão. Não é suficiente preparar os estudantes para o mercado, sobretudo para a vida. Saber pensar inclui necessariamente inserir-se no mercado e também confrontar-se com ele.

Formar cidadãos para o trabalho significa provê-los de um ensino de qualidade, reflexivo e participativo. Há de se fomentar a diversificação dos modos de ensinar e aprender, de observar e criticar, de criar e recriar conhecimentos. Há de se propiciar aos alunos oportunidades efetivas de interação com a realidade do trabalho. Nessa interação, permeada por reflexões teóricas e práticas, o aluno será municiado para uma intervenção não apenas no saber, mas no saber fazer.

Nessa perspectiva, o aluno é construtor de seu conhecimento a partir da reflexão e indagação sobre sua prática, e a sua participação no processo de formação de- verá se dar de modo ativo, num exercício contínuo, provocado e instrumentalizado pelo professor, tendo como objetivo mútuo o comprometimento com a formação de um profissional técnico, competente e, sobretudo ético.

Os diferentes espaços de conhecimento e a conectividade global revolucionam as próprias bases da nossa organização social. A educação deixa de ser um universo em si. Torna-se uma articuladora dos diversos espaços do conhecimento. Esses espaços hoje se comunicam naturalmente, tendo como denominador comum os fluxos de dados e informações em rede.

É necessário, portanto, repensar a educação formal no contexto da Sociedade do Conhecimento. Ao considerá-la como atividade central e organizadora, e não mais como eixo único de formação, abrese a escola para o mundo, pois alunos e professores constroem suas visões de mundo a partir de um conjunto de espaços que hoje trabalham o conhecimento.

A conexão da escola com os diversos universos é possível pelas tecnologias de comunicação e informação, pelas comunidades de aprendizagem, pelos convênios com emissoras de TV, pelas teleconferências com membros da comunidade sobre problemas locais, pelas entrevistas on-line com especialistas sobre um problema dis- 
cutido em aula ou pelo uso de diversas abordagens pedagógicas.

Pode-se dizer que o processo de aprendizado nas organizações educativas, ainda que não formalizado, tem sido pautado no conceito de comunidades de aprendizagem. Nessas comunidades, os professores e estudantes têm em comum um empreendimento (o curso, o conhecimento), o engajamento mútuo (comprometimento e resposta adequada às ações) $e$ um repertório compartilhado (histórias, formas de realizar as tarefas, discursos e estilos). Neste particular, participação e o aprendizado estão profundamente interligados, gerando a possibilidade de negociação de significados entre alunos e professores.

Para muitas pessoas, o conceito de aprendizagem remete imediatamente a imagens de sala de aula, sessões de treinamento, professores, livros, textos, tarefas e exercícios. No entanto, mesmo no contexto escolar, a aprendizagem é uma parte das experiências de vida e da participação das pessoas em comunidades e organizações.

Embora não tenha se constituído em objeto de ação metodológica por parte dos professores que realizaram o PIGI, o conceito de comunidades de prática e aprendizagem permeou as atividades desenvolvidas durante o Projeto. Validou-se, na ob- servação das atividades, o princípio de que os indivíduos (alunos) são sujeitos ativos, com posições críticas, que, na condição de agentes complexos, constroem os contextos nos quais agem e se movimentam.

\section{COMUNIDADES DE APRENDIZAGEM}

O conceito de comunidades de aprendizagem está estritamente associado ao conceito de "Comunidades de prática" CoPs, cunhado por Etienne Wenger e se refere a grupos informais de pessoas que se formam espontaneamente. Segundo WENGER (1998, p.7), "comunidades de prática são partes integrantes de nossas vidas. Elas são tão informais que raramente se tornam explícitas, porém por esta razão elas são tão familiares". Estão distribuídas nas diversas situações do diaa-dia das pessoas, seja na escola, seja no trabalho, ou no lazer (WENGER; McDERMOTT; SNYDER, 2002).

No contexto das organizações, para Terra (2003), as CoPs são um fenômeno recente e trata-se de um conceito essencial na era do conhecimento. O conhecimento humano não faz sentido sem o contexto das comunidades.

As CoPs vão além das estruturas formais da organização, bem como diferem de grupos ou equipes de trabalho. Os membros de uma comunidade podem fazer 
parte de um mesmo departamento ou ser de áreas diversas ou de diferentes instituições. A participação de cada membro pode variar de intensidade, indo desde pessoas que participam de vez em quando para saber o que está acontecendo até líderes (WENGER, 1998).

Dentro das Comunidades de Práticas, as pessoas trocam experiências. Segundo Wenger, McDermott e Snyder (2002, p. 4)

durante o tempo que passam
juntas, as pessoas compartilham
informação, insight e conselhos.
Discutem sobrem determinadas
situações, suas aspirações e suas
necessidades. (....) Elas podem
criar instrumentos, designs, ma-
nuais e outros documentos ou
simplesmente o conhecimento
tácito compartilhado".

Segundo WENGER (1998), o conceito de prática se refere ao "fazer" dentro de um contexto histórico e social que fornece estrutura e significado para o que é feito. $O$ conceito de prática inclui o explícito e o tácito. A comunidade de prática

inclui o tácito e o explícito; o que é dito, e o que é deixado de dizer; o que é representado, e o que é assumido. Inclui a linguagem, ferramentas, documentos, imagens, símbolos, regras bem-definidas, critérios específicos, procedimentos codificados, regras e contratos que as várias práticas tornam explícitos para uma variedade das finalidades (WENGER, 1998, p.47).

Pela ótica da Teoria Social do Aprendizado, defendia por Wenger (1998), o poder do conceito de aprendizado nas comunidades de prática encontra-se na integração de quatro componentes: o significado, a prática, a comunidade e a identidade

- Significado - É a maneira como as pessoas falam sobre habilidades, (individuais ou coletivas) de experimentar a vida e o mundo de forma significativa.

- Prática - É a forma de falar de recursos histórica ou socialmente compartilhados, de estruturas que podem sustentar o engajamento mútuo nas ações em organizações de trabalho.

- Comunidade - É a forma de falar sobre as configurações sociais nas quais os empreendimentos são vistos como possuidores de valor e a participação de um membro é reconhecida como competência.

- Identidade - É a maneira de falar sobre como o aprendizado muda a pessoa e cria histórias pessoais de pertencimento no contexto das comunidades que ela participa (WENGER, 1998, p. 5).

O domínio, área de interesse ou conhecimento, é que determina as atividades que serão realizadas em conjunto. É nele que reside o foco de aprendizado de um empreendimento. Ao lado desse aprendizado específico desenvolvem-se, em cada um dos quatro componentes descritos anteriormente, outros tipos de aprendizado: na comunidade, aprende-se também como pertencer a um empreendimento; na prática, desenvolve-se o aprendizado de como fazer determinada atividade; a negociação de significados articula os aprendi- 
zados sobre como experimentar novas e diferentes visões sobre um determinado assunto; no desenvolvimento da identidade, estão os aprendizados sobre como se tornar uma determinada pessoa.

Ao socializar e externalizar o conhecimento, as pessoas utilizam-se de símbolos, da linguagem, de imagens e outros meios para compartilhar até mesmo o que não é dito, ou seja, o conhecimento tácito. Ressalta-se que pelas comunidades de prática e de aprendizagem é possível, no ambiente universitário, impulsionar a criação do conhecimento.

O conhecimento necessita ser apresentado em um contexto autêntico e a aprendizagem requer interação social e colaboração entre os membros de uma comunidade de prática ou aprendizado. As comunidades de aprendizagem podem ser formadas por estudantes e professores engajados em projetos. Nesses projetos, a aprendizagem será propiciada pela interação das pessoas na solução de problemas, por meio do conhecimento adquirido em perspectivas interdisciplinares.

É imprescindível considerar o respaldo institucional ou organizacional, sem o qual se torna impossível realizar qualquer política de ensino-aprendizagem. Reorganizar a instituição acadêmica ou reorganizar estruturas que envolvam atividades escolares significa ter em mente que ensi- nar é possibilitar troca e criação de conhecimentos. O trabalhador do conhecimento, nesse contexto, deve ter abertura para inovações e articulações com os diversos espaços do conhecimento e com as inúmeras possibilidades oriundas dessas interações.

\section{PROJETO INTEGRADO EM GESTÃO DA INFORMAÇÃO}

Como discutido anteriormente, currículos e atividades didáticas exigem renovação constante a fim de envolver e motivar os alunos na busca de informação e conhecimento. A dinâmica de aprendizagem integrada deve permear o currículo, oferecendo ao discente tanto a organicidade de conteúdos, como o domínio de ferramentas de trabalho e pesquisa. Não raras vezes, o discente aceita a compartimentalização de conteúdos em diferentes disciplinas, exigindo um esforço adicional tanto do professor quanto do aluno - na interligação de temas, no uso de procedimentos e na transposição de elementos que extrapolam o momento didático definido nas fronteiras da disciplina ela mesma.

Além disto, o perfil do estudante (não apenas universitário) do século XXI caracteriza-se por uma significativa resistência às aulas expositivas e pela preferência pelo trabalho prático diante da discussão teórica, em grande parte respaldada pela 
quantidade, diversidade e disponibilidade de estímulos informativos e o acesso às tecnologias de comunicação. Considerando-se ainda, que a própria sociedade tem "flexibilizado" conceitos relativos à ética e à responsabilidade, o ambiente de ensino precisa ser encorajador, desafiante e com uma carga de retorno suficientemente "competitiva" frente aos demais estímulos oferecidos pela sociedade de consumo (MARCHIORI, 2007).

Sob essa perspectiva, duas experiências didático-pedagógicas foram implementadas no escopo do Curso de Gestão da Informação nos anos de 2004 e 2005. No ano de 2004, professores de duas disciplinas do segundo semestre do primeiro ano utilizaram o trabalho final das respectivas disciplinas como um espaço de integração de conteúdos, conhecimentos e habilidades. Procurou-se racionalizar o peso das atividades, solicitando-se que esse único trabalho final englobasse itens que atendessem - organicamente - as demandas de ambas as disciplinas. Alguns destes itens foram comuns, enquanto outros foram especificados conforme cada disciplina. Procurou-se discutir uma plataforma única de avaliação, tendo em vista que problemas encontrados em itens dedicados à determinada disciplina fossem verificados mais profundamente, dada a possibilidade de afetar itens da outra disciplina. A característica de trabalho em grupo e de abor- dagem mais descritiva auxiliou na consecução desta primeira experiência, ainda que, para alguns grupos, a intenção da proposta apenas tenha se aclarado após a correção e explicações finais. Da mesma forma, os discentes se auto-avaliaram e consideraram que a proposta de integração de disciplinas necessitava de maior amadurecimento.

Com as discussões de modificação curricular acontecendo no âmbito do Curso de Gestão da Informação, nova oportunidade ocorreu no semestre seguinte (primeiro semestre de 2005). Os professores envolvidos na primeira experiência consultaram os demais discentes envolvidos nas cinco disciplinas a serem oferecidas para o terceiro ano do Curso. Após algumas reuniões de trabalho, os professores elaboraram um documento intitulado "Projeto Integrado de Gestão da Informação - PIGI" e abriram uma lista de discussão para a troca de idéias e materiais.

O objetivo principal do PIGI foi o de estabelecer uma proposta comum às disciplinas, promovendo uma compreensão mais consistente e estruturada dos processos, produtos, sistemas, serviços relativos à gestão da informação. O resultado pretendido - dentro dos limites estabelecidos pelos professores engajados - compunhase de um trabalho que contemplasse conteúdos verificados nas disciplinas envolvi- 
das. Pretendeu-se, dentro do possível, racionalizar o trabalho dos docentes e discentes envolvidos, estabelecendo "âncoras" de conhecimentos paralelos ou hierarquizados entre as disciplinas, assim como verificando os objetivos, as características e os ferramentais a serem explorados que poderiam servir ou integrar-se em um único trabalho final.

Cinco disciplinas, e respectivos professores e alunos, tomaram parte nesta experiência. Os objetivos e propostas de trabalho seguem abaixo:

\section{Gerenciamento de Acervos Informacionais}

O gerenciamento de acervos informacionais pressupõe a investigação de determinado ambiente organizacional em busca dos diferentes tipos e funções dos documentos gerados pela organização no desempenho de suas atividades. Como parte do reconhecimento do terreno de informações registradas (documentos) no qual o gestor estará interferindo e resolvendo problemas, é importante que o inventário seja de fato um espelho documentário da organização, esclarecendo a origem, a circulação e o valor para a organização dos documentos identificados. Esse diagnóstico especial fornece os elementoschave para o trabalho de gestão de documentos propriamente dito, que incluirá processo de análise e seleção/avaliação do material identificado, com o estabelecimen- to de critérios e prazos de guarda e preservação para acesso dos conjuntos documentais da organização. A interface com o PIGI repousa na elaboração de uma proposta de gestão de documentos em ambiente organizacional.

\section{Monitoramento da Informação}

O monitoramento da informação pressupõe investigar o ambiente em busca de informação pertinente (eventos técnicocientíficos ou sócio-econômicos entre outras inúmeras fontes), definir ameaças potenciais e buscar, nessas ameaças, oportunidades para mudanças ambientais. Compete ao monitoramento alertar a administração quanto ao movimento convergente, divergente, acelerador ou desacelerador das tendências, dando apoio a decisões, planejamento, acompanhamento e avaliação. No que diz respeito ao PIGI, os alunos - em equipe - escolhem uma organização, elaborando um diagnóstico (descrição da estrutura, cultura, estratégias entre outros aspectos), propondo estratégias de inteligência competiviva ou de gestão do conhecimento.

\section{Consultoria em Informação}

A consultoria pressupõe a prestação de serviços para uma empresa-cliente, a começar pelo diagnóstico e identificação das necessidades do cliente. O passo seguinte deverá conduzir a apresentação de 
soluções e ações de melhorias para alavanca os negócios da empresa e do consultor. Os pontos trabalhados no PIGI consideram dois aspectos: a caracterização (como identificação do problema-alvo, foco do projeto de consultoria; análise do ambiente do projeto; definição de objetivos, desafios e metas a serem alcançadas) e a execução (como utilização dos recursos disponíveis de acordo com o programado; cronograma de acompanhamento e controle de atividades).

\section{Fontes de Informação em Ciências Biológicas}

A disciplina de Fontes de Informação em Ciências Biológicas é parte do eixo curricular "Fontes de Informação". Considerando que, previamente à $\mathrm{FICB}$, os alunos cursaram duas outras disciplinas do eixo, elementos básicos foram discutidos, tais como: negociação de demanda, mecanismos de busca em bases de dados e conceitos-base sobre as dimensões das fontes de informação como serviço e produto. A integração da disciplina no PIGI se dá pela estruturação de um guia de informação eletrônico abordando alguma sub-área das Ciências Biológicas, da Saúde ou Agrárias.

\section{Banco de Dados}

Laboratório de Bancos de Dados é uma disciplina instrumental, que provê os alunos dos conceitos e práticas relativas ao desenho, projeto e implementação de ban- cos de dados. A disciplina oferece suporte para um produto de informação, a ser criado pelos alunos de acordo com as necessidades organizacionais e ambientais encontradas nas pesquisas realizadas nas demais disciplinas. $\mathrm{O}$ apoio, no escopo do PIGI, reflete-se nas seguintes fases: a) Modelagem Entidade $x$ Relacionamento: levantamento das necessidades e metadados necessários à realização do projeto; desenho do Banco de Dados; b) Modelagem Relacional: Projeto do Banco de Dados e das consultas a serem realizadas; $\mathrm{c}$ ) Implementação e testes do Banco de Dados gerado, com Interface via Intranet.

Observa-se que as disciplinas de Bancos de Dados e Fontes de Informação em Ciências Biológicas apontaram para a elaboração de um produto de informação, apoiado por um projeto escrito com base nos parâmetros estabelecidos pelas disciplinas Gerenciamento de Acervos Informacionais, Monitoramento da Informação e Consultoria em Informação.

O público-alvo do PIGI compôs-se de alunos regulares do primeiro semestre de 2004. Os professores ministraram suas disciplinas consoante o seu plano de ensino, tendo sido acordados: a estrutura desse trabalho final, datas de início e término/entrega e apresentação oral do trabalho em um seminário também integrado. 
4.1 Metodologia do Projeto Final e Forma de Avaliação

Uma vez definido o escopo de cada disciplina, o grupo de professores organizou um roteiro de orientação das atividades, definindo datas para atividades de campo.

O projeto final exigia um documento escrito relacionando aspectos de consultoria, inteligência competitiva e gerenciamento documentário (entregues na forma de uma cópia impressa e uma digital), além do detalhamento do desenho entidaderelacionamento do banco de dados (projeto relacional, scripts de acesso/manipulação ao banco de dados), o qual deveria configurar-se como um produto de informação (guia de informação em área/sub-área das Ciências Biológica, da Saúde ou Agrárias). Em particular, para estas duas disciplinas, as equipes deveriam entregar um "Diário de Atividades", descrevendo problemáticas e soluções encontradas na execução do produto informativo.

No caso da ocorrência de alunos não matriculados simultaneamente nas cinco disciplinas, ou para aqueles que por qualquer razão trancaram ou desistiram de qualquer uma delas, foi facultado o direito de não participar de equipes de projeto conjunto. Nesses casos, cada professor propôs trabalhos específicos com igual teor de dificuldade, de forma a não modificar o critério de avaliação. Outros casos não previstos foram discutidos pelos professores e alunos interessados, sem prejuízo do acompanhamento, aproveitamento e avaliação dos alunos, individual ou coletivamente. Cada professor avaliou a conformidade do trabalho escrito (ou produto informacional) segundo critérios previamente definidos junto aos alunos. Cada trabalho foi avaliado em separado sob a ótica de cada disciplina/professor envolvido, gerando notas potencialmente diferentes para cada projeto. A sessão de apresentação dos trabalhos em seminário único, ao final do semestre, envolvendo as disciplinas Gerenciamento de Acervos Informacionais, Monitoramento da Informação e Consultoria em Informação, permitiu uma préavaliação do estudo feito e o questionamento - docente e discente - sobre aspectos de interesse.

\subsection{Resultados da Avaliação do PIGI}

Durante sua aplicação, o PIGI, enfrentou dificuldades, tais como:

- adequação do número e composição dos grupos de alunos (equipe), que pudesse atender a todas às disciplinas de forma orgânica. Alguns alunos estavam matriculados em todas as disciplinas, enquanto outros em apenas algumas. Grupos definidos para, por exemplo, três disciplinas não estariam coesos para outras duas; 
- localização e identificação de empresas ligadas à área de ciências biológicas, saúde e agrárias na Região Metropolitana de Curitiba;

- aceitação e permanência da equipe na empresa, do início ao fim do projeto (empresários desistiram de fornecer os dados necessários; outro foi acometido de um problema de saúde - entre outros casos -, provocando mudança no trabalho e busca de outra organização, com prejuízo de tempo e coleta de dados já realizada);

- incompatibilidade de horários dos professores para otimização do projeto;

- descompasso, entre as disciplinas, quanto ao tempo necessário para a apreensão de suporte teórico e de conteúdos antes da saída a campo;

- receio, entre os professores, de que conteúdos específicos não fossem explorados (dado o foco no PIGI), ocasionando um efeito contrário, em que o peso e o tempo dado a demais trabalhos complementares diminuiu a disponibilidade integral ao PIGI.

A dificuldade de identificar empresas com atuação em Ciências Biológicas dispostas a ceder informações para o trabalho causou um desmembramento nas condições de trabalho do PIGI. As disciplinas de Fontes de Informação em Ciências Biológi- cas e de Banco de Dados efetivaram uma parceria adequada sob o ponto de vista do produto de informação. Algumas equipes, em esforço extra, não só atingiram os objetivos específicos voltados para o trabalho, mas lograram inserir o material coletado em uma base de dados com acesso via uma interface web. Para outras equipes, foi facultada a apresentação em outros formatos eletrônicos (interface web com base em links de hipertexto; interface web com base em arquivo do MSPower Point ou MSWord, por exemplo).

Para as disciplinas de Gerenciamento de Acervos Informacionais, Monitoramento da Informação e Consultoria em Informação, os alunos apresentaram o trabalho na forma oral, entregando cópia em papel. Igualmente, foram estimulados a avaliar o PIGI (de forma anônima) com base num instrumento contendo itens voltados para o tratamento dos conteúdos destas três disciplinas, as estratégias didáticas dos professores, a avaliação da aprendizagem (aspectos positivos e negativos) e apresentação de sugestões para melhorar o projeto. Abaixo, apresentam-se os resultados.

\subsubsection{Tratamento dos Conteúdos das disciplinas}

Participaram desta avaliação 17 alunos matriculados nas disciplinas "Gerenciamento de Acervos Informacionais", "Monitoramento da Informação" e "Consultoria 
em Informação". Este número correspondente a $100 \%$ do total de alunos envolvidos no PIGI que apresentaram seus projetos finais em única apresentação aos professores das disciplinas acima referenciadas. Buscou-se que os discentes avaliassem os conteúdos quanto a: coerência dos objetivos do curso; nível de atualização dos conteúdos; pertinência dos conteúdos e suas necessidades profissionais; bibliografia indicada para consulta e relação entre o conteúdo e seu aproveitamento.

A Tabela 1 apresenta as estatísticas relativas a coerência dos objetivos do curso com os conteúdos apresentados nas disciplinas.

Tabela 1: Coerência dos objetivos do curso com os conteúdos

\begin{tabular}{l|c|c}
\hline \multicolumn{1}{c|}{ Conteúdo } & N. Citações & Freq. (\%) \\
\hline Insuficiente & 0 & 0,00 \\
\hline Regular & 1 & 5,88 \\
\hline Bom & 4 & 23,53 \\
\hline Muito bom & 5 & 29,41 \\
\hline Ótimo & 7 & 41,18 \\
\hline \multicolumn{1}{r|}{ Total } & $\mathbf{1 7}$ & $\mathbf{1 0 0}$ \\
\hline
\end{tabular}

A partir da tabela acima é possível verificar que o projeto foi avaliado positivamente no quesito Coerência dos objetivos do curso com os conteúdos, com 70,6\% entre ótimo e muito bom. Essa mesma dis- tribuição favorável ocorreu em relação aos itens Objetivos dos conteúdos, Nível de atualização e Indicação de bibliografia $(70,59 \%)$, conforme se observa na Tabela 2.

Tabela 2: Tratamento dos conteúdos das disciplinas - Combinação simples dos itens

\begin{tabular}{|c|c|c|c|c|c|c|}
\hline & Insuficiente & Regular & Bom & Muito bom & Ótimo & Total \\
\hline 1. Objetivo dos conteúdos & $0,00 \%$ & $5,88 \%$ & $23,53 \%$ & $29,41 \%$ & $41,18 \%$ & $100 \%$ \\
\hline 2. Nível de atualização & $0,00 \%$ & $17,65 \%$ & $11,76 \%$ & $29,41 \%$ & $41,18 \%$ & $100 \%$ \\
\hline $\begin{array}{l}\text { 3. Pertinência dos } \\
\text { conteúdos }\end{array}$ & $5,88 \%$ & $11,76 \%$ & $35,29 \%$ & $11,76 \%$ & $35,29 \%$ & $100 \%$ \\
\hline 4. Indicação de bibliografia & $0,00 \%$ & $5,88 \%$ & $23,53 \%$ & $23,53 \%$ & $47,06 \%$ & $100 \%$ \\
\hline $\begin{array}{l}\text { 5. Relação conteúdo } x \\
\text { aproveitamento }\end{array}$ & $0,00 \%$ & $11,76 \%$ & $29,41 \%$ & $23,53 \%$ & $35,29 \%$ & $100 \%$ \\
\hline
\end{tabular}

Relação conteúdo $\mathrm{x}$ aproveitamento e Pertinência dos conteúdos receberam avaliação de muito bom e ótimo com índices de $58,82 \%$ e $47,05 \%$, respectivamente To- dos os itens avaliados receberam índices entre bom, muito bom e ótimo superiores a $82 \%$. 


\subsubsection{Estratégias Didáticas dos Professores}

Neste item, solicitou-se aos participantes que avaliassem: utilização adequada dos recursos didáticos; qualidade dos recursos para motivação e compreensão dos conteúdos; carga horária; atendimento individualizado e satisfação das expectativas.
Destaca-se na Tabela 3 que Carga horária foi o único item avaliado como regular/insuficiente $(35 \%)$. Para Recursos didáticos em uso e Atendimento individualizado o índice ótimo obteve 59\% e 53\%, respectivamente. Para Qualidade de recursos, o índice mais citado foi muito bom $(41 \%)$.

Tabela 3: Itens mais citados - Estratégias Didáticas dos Professores

\begin{tabular}{|c|c|c|c|}
\hline & $\begin{array}{c}\text { Categoria citada em } \\
\text { n. } 1\end{array}$ & $\begin{array}{c}\text { Categoria citada em } \\
\text { n. } 2\end{array}$ & $\begin{array}{c}\text { Categoria menos } \\
\text { citada }\end{array}$ \\
\hline $\begin{array}{l}\text { 1. Recursos } \\
\text { didáticos em uso }\end{array}$ & Ótimo (10) & Muito bom (3) & Insuficiente (0) \\
\hline $\begin{array}{l}\text { 2. Qualidade dos } \\
\text { recursos - motivação }\end{array}$ & Muito bom (7) & Bom (4) & Insuficiente (0) \\
\hline 3. Carga Horária & Regular (6) & Bom (4) & Insuficiente (2) \\
\hline $\begin{array}{l}\text { 4. Atendimento } \\
\text { individualizado }\end{array}$ & Ótimo (9) & Bom (5) & Regular (0) \\
\hline $\begin{array}{l}\text { 5. Satisfação das } \\
\text { expectativas }\end{array}$ & Muito bom (9) & Bom (3) & Insuficiente (0) \\
\hline
\end{tabular}

O índice de satisfação das expectatimanifestando satisfação entre muito bom e vas é apresentado no gráfico 1 , com $71 \%$ ótimo.

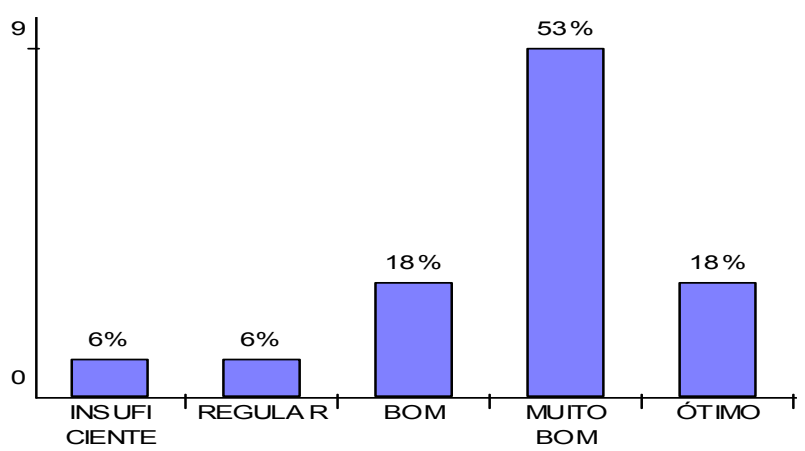

Gráfico 1 - Satisfação das expectativas

4.2.3 Avaliação da aprendizagem - pes- $\begin{array}{r}\text { Solicitou-se ainda que os alunos fi- } \\ \text { soal }\end{array}$
zessem uma avaliação individual quanto à 
sua aprendizagem, ou seja, nível de aproveitamento individual e participação nas tarefas das disciplinas.

O Gráfico 3 evidencia que os alunos consideram ter obtido aproveitamento de muito bom para ótimo, com índices respectivos de $41 \%$ e $35 \%$. Esses índices são muito próximos dos relativos à participação nas tarefas das disciplinas (tabela 4).

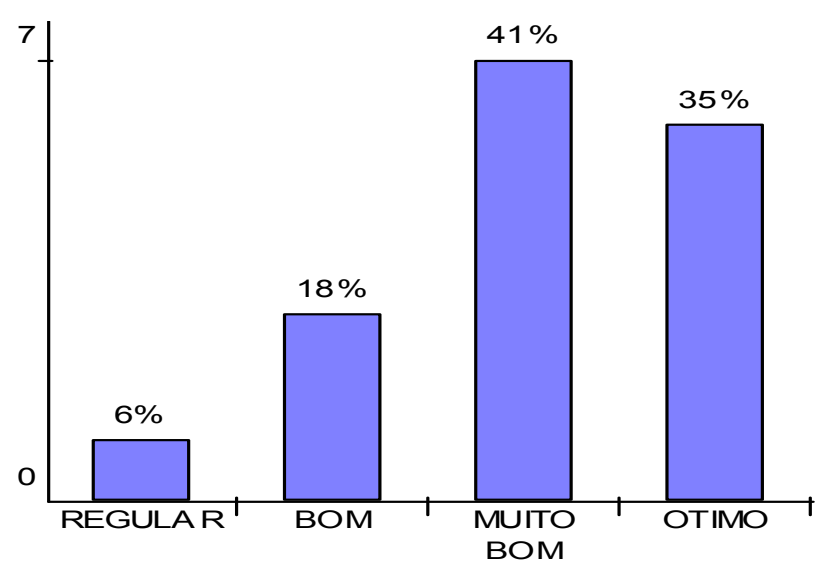

Gráfico 3 - Nível de aproveitamento individual

Os índices Nível de aproveitamento individual (gráfico 3) superam $84 \%$, somando-se de bom a ótimo, fato que com- prova os dados da Tabela 3, em que os discentes aprovam as estratégias didáticas dos professores no PIGI.

Tabela 4: Participação nas tarefas das disciplinas

\begin{tabular}{l|c|c}
\hline \multicolumn{1}{c|}{ partic. tarefas } & N. Citações & Freq. (\%) \\
\hline Insuficiente & 0 & 0 \\
\hline Regular & 1 & 6 \\
\hline Bom & 2 & 12 \\
\hline Muito bom & 9 & 53 \\
\hline Ótimo Total & 5 & 29 \\
\hline & $\mathbf{1 7}$ & $\mathbf{1 0 0}$ \\
\hline
\end{tabular}

Finalmente, a Tabela 4 apresenta a avaliação dos alunos quanto à sua própria participação nas atividades propostas nas disciplinas com $94 \%$ de satisfação. Apesar dessa avaliação positiva, reclamaram de algumas dificuldades, conforme se observa no item a seguir.

\subsubsection{Análise Crítica e Sugestões para Melhorar o Projeto}

$\mathrm{Na}$ avaliação dos alunos ao PIGI, as principais respostas levantando aspectos positivos podem ser classsificadas em três grandes categorias integração, mercado de trabalho e prática. 
Integração

No que se refere à integração os alunos indicaram como elementos positivos:

- a proposta em si que possibilitou maior integração en-tre os alunos e os professores, ampliando a visão profissional (mercado);

- iniciativa de integração entre as disciplinas em um único trabalho, facilitando aplicação da teoria na prática;

\section{Mercado de trabalho}

Com relação ao mercado de trabalho os aspectos positivos apontados foram:

-interação entre o meio acadêmico e profissional, permitindo experiência para o mercado de trabalho;

-a intenção do projeto é ótima, tende a nos preparar realmente para o mercado de trabalho;

- contato com o mercado de trabalho e conhecimento das áreas em que é possível haver o trabalho do gestor da infor-mação;

\section{Prática}

Como pontos relevantes na categoria prática foram indicados:

- trabalho realizado na prática, o que mostra o que é na realidade a aplicação do aprendizado;

- matérias com mais sentido, com relação ao que está acontecendo no mercado, e fácil de colocar em prática;

- trabalho prático - aplicação direta do aprendizado na empresa.
- conhecimento prático da disciplina de Consultoria, com todas as dificuldades de negociação com o cliente;

Quanto aos aspectos considerados negativos, as respostas podem ser classificadas em três grandes categorias: dificuldade de interação com as organizações, tempo inadequado e excesso de atividades e docentes /conteúdos.

Dificuldade de interação com as organizações

Os alunos indicaram como dificuldades:

- dificuldade em interagir com as empresas

- as equipes se oferecem para fazer o trabalho, isso não traz muito interesse por parte das organizações;.

\section{Tempo inadequado e excesso de ativi- dades}

No que se refere as atividades previstas no projeto e o tempo para realizá-las foram apontados como fatores negativos:

- o tempo proposto para realização e apresentação do pro-jeto;

- falta de tempo para elaboração do projeto, visto que em paralelo houve a realização de outros trabalhos;

- conteúdo muito grande para um semestre

- acúmulo de tarefas, preju-dicando o bom andamento do projeto 
- trabalhos paralelos durante o tempo destinado ao projeto integrado, dificultando uma dedi-cação maior ao mesmo;

\section{Docentes/conteúdos}

Em relação aos professores e conteúdos foram indicados os seguintes pontos negativos:

- dificuldades em integrar os objetivos de cada professor no projeto;

- alguns professores não deram a devida importância ao projeto integrado

- repetição do pedido de alguns itens (conteúdos);

- imposição de trabalhos em empresa com foco nas Ciências Biológicas.

- falta de disciplinas como negociação, marketing, oratória;

Destaca-se que $100 \%$ dos alunos reclamaram do excesso de atividades paralelas nas disciplinas, o que impediu um aprofundamento no trabalho de integração dos conteúdos.

Como sugestão para melhoria do projeto, obteve-se como contribuição:

- foco real num único projeto;

- maior o tempo para realização do trabalho e da apresentação final;

- uma coordenação geral que oriente um encaminhamento geral;

- não impor o que fazer, mas obter do cliente o que deseja;

- reservar o semestre para atuação junto às empresas, oportunizando mais ofertas de estágios;
- divulgar junto às empresas essas possibilidades de atuação dos gestores;

- liberdade para escolher a empresa onde pode realizar o trabalho;

- aumentar a carga horária da disciplina de Monitoramento da Informação;

•implantação de uma disciplina de projetos;

-integração dos professores com as empresas.

O resultado geral, ainda que satisfatório, exige reflexão e adequação da proposta. Na medida do possível, os ajustes serão realizados com base nos aspectos positivos e negativos elencados pelos alunos e identificados pelos próprios professores envolvidos. Um exame cuidadoso da experiência servirá não só para a melhoria de conteúdo e didática de cada disciplina, mas, principalmente, para viabilizar uma próxima edição da experiência de forma mais orgânica.

\section{CONSIDERAÇÕES FINAIS}

A partir da experiência relatada, algumas considerações destacam-se na expectativa de contribuir para a melhoria da formação dos gestores de informação:

1. Merece atenção a possibilidade de unir disciplinas com conteúdos ajustados às demandas do mercado e a projetos de desenvolvimento do País, de modo a integrar o acadêmico ao mundo de trabalho. 
2. Deve-se incentivar aqueles projetos que busquem integrar a Academia às organizações do mundo do trabalho, unindo formação e produtividade. A nitidez destas ações contribuirá para estimular mais abertura nas organizações para o trabalho acadêmico e geração de estágios profissionais, trazendo confiança à atuação/interferência da universidade nos aspectos de mercado.

3. A metodologia de ensino precisa ser (re) pensada, em que os planos de ensino possam contemplar e integrar diferentes finalidades no âmbito das atividades a serem exercidas pelo acadêmico.

4. Devem-se reforçar, nas práticas universitárias, projetos experimentais envolvendo grupos de alunos/ professores com aplicação de metodologias similares àquelas empregadas em comunidades de prática e de aprendizagem. Tais projetos devem ser avaliados em todos os níveis, a começar pela satisfação dos participantes, quer alunos, quer professores.

5. É oportuno resgatar que o conceito e as metodologias utilizadas pelas comunidades de prática podem ser amplamente aproveitados em organizações escolares. Elas são os recursos de conhecimento mais dinâmicos e versáteis. Nelas as interações realizadas no dia-a-dia são tão naturais e inerentes à vivência das pessoas que, muitas vezes, nem são percebidas ou questionadas. Dessa forma, o fio condutor do PIGI amparado no conceito de comunidades de prática pode contribuir para 0 entendimento das relações entre professores e alunos, na construção e compartiIhamento de conhecimento.

De um ponto de vista mais amplo, evidenciam-se na experiência do PIGI os elementos "prática" e "compartilhamento", o que sinaliza a efetivação possível, nesse ambiente acadêmico, de uma comunidade de aprendizagem.

Por outro lado, destaca-se nessa experiência o signo forte e maduro do diálogo e do compromisso, o movimento de esforço de uma equipe interessada em um aprender/saber/fazer que só faz sentido no coletivo. Evidencia-se que a força de um grupo (se verdadeiramente grupo, pessoas em processo de colaboração) objetivamente sustenta o desafio de uma empreitada, diluindo ou amenizando o lado negativo dos inevitáveis embates e conflitos de toda ordem, aparando medos, dúvidas e ansiedades, minimizando o peso de erros, limitações, fragilidades, contornando crises inférteis, e assim possibilitando o início de uma construção coletiva, altamente pedagógica para todos os envolvidos.

Para sublinhar o reconhecimento da dimensão formativa da experiência, vale recorrer a Larrosa (1996), que decompõe o termo experiência: "ex" significa pôr para 
fora, extrair de; "per" diz respeito a percurso, travessia, perigo/risco/aventura; "iência" refere-se a um novo estado de ser e saber ou a um novo sentido de quem somos. Lembra o autor que uma experiência genuinamente formativa equivale "não ao que passa, senão o que nos passa" (FIORENTINI, MIORIM, 2001, p. 37)

Deixa-nos esta reflexão com o pensamento voltado para o horizonte das possibilidades de professores pesquisadores em colaboração, curiosos em relação ao tema e ao universo de experiências afins.

\section{REFERÊNCIAS}

BERGMAN, P. I.; LUCKMANN, T. A construção social da realidade. Rio de Janeiro: Vozes, 1985.

DELORS, J. Educação: um tesouro a descobrir. São Paulo: Cortez, 1999.

FIORENTINI, Darío; MIORIM, Maria Ângela (Orgs.). Por trás da porta, que matemática acontece? Campinas: Ed. Graf. FE/Unicamp, 2001.

LARROSA, Jorge. La experiência de la lectura: estudios sobre literatura y formación. Barcelona: Laertes, 1996.

MARCHIORI, P. Z. Ensino, pesquisa e extensão em Gestão da Informação. In: RIBEIRO, Maria Solange Pereira et al. (Org.) Pesquisa, conhecimento e práticas sociais em Ciência da Informação. São Luis: Edufma, 2007.

TERRA, J. C. C. Gestão do conhecimento e e-learning na prática. Rio de Janeiro: Elsevier, 2003.
WENGER, E. Communities of practice: learning, meaning and identity. Cambridge: Cambridge University Press, 1998.

WENGER, E.; McDERMOTT, R.; SNYDER, W. M. Cultivating communities of practice. Boston: Harvard Business School, 2002.

\section{Maria do Carmo Duarte Freitas Doutora em Engenharia de Produção. Profes- sora Adjunta do Departamento de Ciência e Gestão da Informação (UFPR) mcf@ufpr.br}

Helena de Fátima Nunes Silva Doutora em Engenharia de Produção. Professora Adjunta do Departamento de Ciência e Gestão da Informação (UFPR) helenanunes@ufpr.br

Patrícia Zeni Marchiori

Doutora em Ciência da Informação. Professora Adjunta do Departamento de Ciência e Gestão da Informação (UFPR) pzeni@ufpr.br

Sônia Maria Breda Mestre em Educação. Professora Assistente do Departamento de Ciência e Gestão da Infromação (UFPR). Doutoranda em Educação breda@ufpr.br 


\section{Title}

Communities of learning: an academic experience in a information management integrated project

\begin{abstract}
This paper describes an educational and teaching experience held at the Universidade Federal do Paraná and under the Departamento de Ciência e Gestão da Informação supervision, which was conducted as an integrated project "Projeto Integrado em Gestão da Informação" (PIGI).. It stimulates a discussion about the present job demands and its relation with the undergratuated education, exposing the PIGI proposal and methodology, as well as the basic concepts of the learning communities. The achieved results and the Project academic contributions are discussed. Some suggestions and improvements are also presented, meanly those related to "practice" and "sharing" concepts, which are milestones towards a professional learning community.
\end{abstract}

\section{Keywords}

Higher Education - teaching methods. University Teaching. Learning Communities - experiences, Information Management - Professional Education.

\section{Título}

Comunidades de aprendizaje: la experiencia académica del proyecto integrado en gestión de la información

\section{Resumen}

Presenta una reflexión sobre la enseñanza superior basada en el reporte de la experiencia del "Projeto Integrado em Gestão da Informação (PIGI) - Proyecto Integrado en Gestión de la Información", del Curso de Gestión de la Información de la Universidad Federal de Paraná. Discurre sobre os trazos distintivos del actual mundo de trabajo y su relaccíon con las carreras universitarias. Expone los fundamentos de las comunidades de aprendizaje. Des- cribe la propuesta y el método del PIGI. Presenta datos de evaluación del Proyecto y resalta las ventajas para profesores y alumnos envolucrados. Presenta sugerencias de perfeccionamiento del proceso formativo del Gestor de Información. Destaca los elementos "practica" e "coparticipación" como los puntos clave de esa experiencia hacia la efectivación de una comunidad de aprendizaje.

\section{Palabras Clave}

Enseñanza superior - metodologías; Comunidad de aprendizaje; Administración de la Información - formación profesional.

Recebido em: 20.04.2007

Aceito em: 20.06.2007 